\title{
Epidemiologic Profile of Cutaneous Leishmaniasis Between 2010 - 2016 in an Endemic Area of Fars Province, South Iran
}

\author{
Jalal Mohammadi ${ }^{1}$ and Aboozar Soltani ${ }^{2,}{ }^{*}$ \\ ${ }^{1}$ Department of Medical Entomology and Vector Control, School of Health, Shiraz University of Medical Sciences, Shiraz, Iran \\ ${ }^{2}$ Research Center for Health Sciences, Institute of Health, Department of Medical Entomology and Vector Control, School of Health, Shiraz University of Medical Sciences, \\ Shiraz, Iran \\ "Corresponding author: Research Center for Health Sciences, Institute of Health, Department of Medical Entomology and Vector Control, School of Health, Shiraz University of \\ Medical Sciences, Shiraz, Iran. Email: abu2sol@yahoo.com
}

Received 2018 November 16; Revised 2019 January 14; Accepted 2019 January 20

\begin{abstract}
Background: Leishmaniasis contains a group of zoonotic diseases that is caused by infected phlebotomine sandflies with flagellate protozoa of the genus Leishmania.

Objectives: The aim of this study was to determine some epidemiological aspects of patients with cutaneous leishmaniasis referring to Marvdasht health center, Fars Province, Iran.

Methods: Demographic and clinical data of all patients recorded in Marvdasht Health Center, the Infectious Diseases Unit from 2010 to 2016.

Results: 7418 confirmed cases of cutaneous leishmaniasis referred to health centers for receiving treatment. The mean age of the patients was $32.9 \pm 26.9$ year and the incidence of disease in men was higher than women. The age group was 21 to 30 years old (22.9\%) had the most cases. The average duration of exposure to detection of the disease was $4.9 \pm 1.38$ months. The prevalence of wet lesions was significantly higher than dry lesions, and the average size of the lesions was $4.27 \mathrm{~cm}$. The average number of lesions was 1.58 per person, and most of them were in hands (39.6\%) and feet (21.4\%). The incidence of disease was higher in the autumn than other seasons and it occurred more in rural areas.

Conclusions: Marvdasht city is an endemic area of cutaneous leishmaniasis in Iran. Our results showed that the number of cases reported has fluctuated in recent years. Therefore, it is very important for the health system to implement an accurate and effective continuous monitoring strategy for this important vector-borne disease in this part of the country.
\end{abstract}

Keywords: Leishmaniasis, Cutaneous, Epidemiology, Endemic Foci, Iran

\section{Background}

The World Health Organization has introduced Leishmaniasis as one of the most important seven tropical diseases all around the world. Leishmaniasis is caused by different species of leishmania. These diseases are transmitted by the bite of infected female sandflies of the genus Phlebotomus in the Old World. There are three basic clinical forms: cutaneous, mucocutaneous, and visceral leishmaniasis $(1,2)$. It has a wide range of different clinical symptoms on humans and animals. Sandflies have very diverse habitats, but they are found mostly in tropical regions, although in recent years the disease has spread to other areas $(3,4)$.

About 12 million people from 88 countries suffer from leishmaniasis, of which 16 are among the developed countries of the world. It is estimated that about 350 million people are at risk for various forms of leishmania- sis. The number of new cases is about 2 million per year (5). Iran is located in the endemic areas of leishmaniasis. Two types of cutaneous leishmaniasis including the urban form with dry lesions, human reservoir, and its vector Phlebotomus sergenti is endemic in Tehran, Kerman, Bam, Mashhad, Nishabur and Sabzevar cities. Another form is rural of which the reservoirs are mainly rats and Gerbillinae rodents, main vector is $P$. papatasi and the cities of Natanz, Isfahan, Shiraz, Sarakhs, Lotf Abad, Kashmar, Baft and Khuzestan province are endemic foci $(6,7)$. Skin lesions caused by Leishmania may take several years until complete recovery if treatment is not taken. In this case, they can be infected with secondary infections such as yaws and myiasis $(1,8)$.

Several studies have shown that leishmaniasis in Iran and all over the world is on the rise. There is no certain cure for it and physicians, based on their experiences besides 
routine drugs, use different treatments and local methods for treatment of their patients. Reports indicate recurrence, poor recovery, or inappropriate treatment of patients $(9,10)$. Because today Leishmaniasis is a serious health problem in some countries including Iran, there is a need for more fundamental research in order to better understand its epidemiology and disease cycle. Fars province is now a focus of endemic cutaneous leishmaniasis due to the spread of the disease in almost all part of the province.

\section{Objectives}

This study aimed to investigate some epidemiologic factors of patients with cutaneous leishmaniasis referring to Marvdasht health center, Fars province, Iran. So that they can be used to better understand the main effective factors in this disease and to apply prophylactic approaches in this endemic area.

\section{Methods}

This descriptive-analytic study was conducted on the epidemiology of cutaneous leishmaniasis from 2010 to 2016. Accordingly, demographic and clinical data of all microscopic approved cases recorded in Marvdasht Health Center, the Infectious Diseases Unit. The routine process of case finding was passive method and in some period of time active case finding was done. Data from people who were not approved microscopically were excluded from the study. Data included demographic information such as age, sex, occupation, place of residence, season, number of lesions, and history of disease.

To analyze the data, descriptive statistics such as mean, standard deviation, percentage estimation and frequency of qualitative data were used. Also, statistical charts such as linear charts were also used. For analysis of variables, independent sample $t$-test and ANOVA were used and analyzed by SPSS version 16 software. The significance level was $5 \%$.

\section{Results}

This study was conducted from 2010 to 2016 in Marvdasht, Iran. Accordingly, during the aforementioned years, 7418 confirmed cases of cutaneous leishmaniasis referred to local health centers for receiving treatment (all participants provided written informed consent). During this period of time, most cases of disease were recorded in 2015 (22.2\%) and the least cases belonged to 2016 (7.1\%) and 2010 (10\%) (Figure 1). There were significant differences between year 2016 and the previous years (except 2010) for mean number of cases. And also there were significant differences between mean number of cases of 2015 and other studied years $(\mathrm{P}$ value $=0.001)$. There were no significant differences between number of cases in two sexes $(P$ value $=$ $0.86), 54.4 \%$ of the cases were men and $45.6 \%$ of cases were women.

In total population, the mean age of patients was 32.9 \pm 26.9 years; this was $32.2 \pm 28.7$ and $33.6 \pm 24.7$ for women and men respectively. There was no statistically significant difference between the mean age of both sexes $(\mathrm{P}$ value $=$ 0.89 ). The highest number of cases of cutaneous leishmaniasis occurred in the 21 to 30 -year-old group, and the least cases were in people over the age of 60 years. $14.6 \%$ of cases were in category of less than 10 years old (Table 1). According to the findings, the highest number of cases of disease occurred in autumn and the least occurred in spring (Table 2). Also, the incidence of diseases in rural areas $(58.4 \%, 95 \%$ CI: $0.5815,0.5864)$ was higher than urban areas $(41.6 \%, 95 \%$ CI: $0.4105,0.4215)$.

The study of the clinical consequences of lesions in people with cutaneous leishmaniasis showed that, the mean duration of exposure until the onset of clinical signs of the disease was estimated to be $151 \pm 55.9$ days. More-

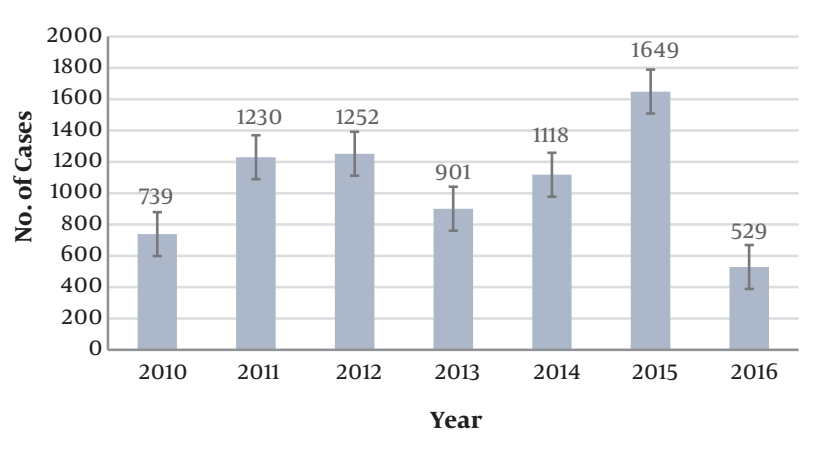

Figure 1. Frequency of cutaneous Leishmaniasis cases in Marvdasht city between 2010 to December 2016

Table 1. Frequency of Cutaneous Leishmaniasis Cases in Different Age Group in Marvdasht City Between 2010 - 2016

\begin{tabular}{lcc}
\hline Age, $\mathbf{y}$ & Frequency & $\%$ \\
\hline$<\mathbf{1 0}$ & 1084 & 14.6 \\
$\mathbf{1 1}-\mathbf{2 0}$ & 954 & 12.9 \\
\hline $\mathbf{2 1}-\mathbf{3 0}$ & 1695 & 22.9 \\
\hline $\mathbf{3 1}-\mathbf{4 0}$ & 1346 & 18 \\
\hline $\mathbf{4 1}-\mathbf{5 0}$ & 1086 & 14.7 \\
\hline $\mathbf{5 1}-\mathbf{6 0}$ & 713 & 9.6 \\
\hline $\mathbf{6 0}>$ & 540 & 7.3 \\
\hline Total & 7418 & 100 \\
\hline
\end{tabular}


over, location of lesions on the face and upper limbs was present $62.8 \%$, on the lower limbs $25.2 \%$, and in $12 \%$ of the cases it was observed in both parts. Most lesions were on the hands and the least cases were on the trunk (Table $3)$. The average number of lesions was 1.588 per person. In 2484 cases only one lesion was recorded, and the least number of lesion was related to the person with 4 and 5 lesions (Table 4).

In all examined patients, the average size of the lesions was $4.27 \mathrm{~cm}$, with the smallest of $1 \mathrm{~cm}$ and the largest of 5 cm wide.

Table 2. Frequency of Cutaneous Leishmaniasis Cases in Different Seasons in Marvdasht City Between 2010 - 2016

\begin{tabular}{lcc}
\hline Season & Frequency & $\%$ \\
\hline Spring & 197 & 2.6 \\
Summer & 1013 & 13.7 \\
\hline Fall & 4119 & 55.5 \\
Winter & 2089 & 28.2 \\
Total & 7418 & 100 \\
\hline
\end{tabular}

\begin{tabular}{|lcc}
\hline Table 3. Frequency of Lesions Caused by Cutaneous Leishmaniasis & \\
\hline Place of Lesion & Frequency & $\%$ \\
\hline Hand & 2937 & 39.6 \\
\hline Face & 695 & 9.4 \\
\hline Trunk & 166 & 2.2 \\
\hline Foot & 1587 & 21.4 \\
\hline Foot and leg & 284 & 3.8 \\
\hline Trunk and foot & 102 & 1.4 \\
\hline Hand and trunk & 332 & 4.5 \\
\hline Hand and foot & 787 & 10.6 \\
\hline Face and trunk & 528 & 7.1 \\
\hline Total & 7418 & 100 \\
\hline
\end{tabular}

\begin{tabular}{lcc}
\hline $\begin{array}{l}\text { Table 4. The Frequency Number of Lesions in Patients with Cutaneous Leishmania- } \\
\text { sis }\end{array}$ & Frequency & $\%$ \\
\hline Number of Lesion & 2485 & 33.5 \\
\hline $\mathbf{1}$ & 1661 & 22.4 \\
$\mathbf{2}$ & 1112 & 15 \\
$\mathbf{3}$ & 571 & 7.7 \\
$\mathbf{4}$ & 573 & 7.7 \\
$\mathbf{5}$ & 1016 & 13.7 \\
$\mathbf{6} \leq$ & 7418 & 100 \\
\hline Total & & \\
\hline
\end{tabular}

\section{Discussion}

According to the results of the present study, the number of cases of disease in males was higher than that of females, but there was no significant difference between average age of morbidity in two sexes. In the study of Nilforoushzadeh et al. 2015 in Isfahan, the rate of disease in men (61.8\%) was higher than that of women (38.2\%) (6). Also, in other studies the percentage of cutaneous leishmaniasis cases in men was reported $64.1 \%$ in Ilam (Ilam province), 56\% in Andimeshk (Khuzestan province), $61 \%$ in Khorasan-Razavi province, $61.8 \%$ in Khatam (Yazd province) and $93.8 \%$ in Hamedan (Hamedan province). In all mentioned studies, morbidity rate was significantly different between males and females (10-14). But unlike previous studies, in Lamerd city (Fars province), the number of cases in women (51.8\%) was higher than men (48.1) (15). The higher morbidity rate of disease in men can be attributed to some reasons such as their higher outdoor activity, less clothing and body coverage (compared to women who wear hijab in Iran), and more contact with vectors.

Our findings showed that the highest number of cases occurred in the age group of 21 - 30 years. In Isfahan, most cases were in the age group of 10 - 30 years and in Andimeshk in the age group of $15-24$ years $(6,12)$. Furthermore, the highest number of cases in Khorasan-Razavi province, Khatam (Yazd province), and Hamedan province were in the age group of under 10 and 20 - 30, 10 - 30, 15 - 24 years old respectively $(10,13,14)$. Our results are in accordance with results of the above studies and suggest that in both sexes, the incidence of disease in young people is higher than in other age groups.

In the present study, the incidence of disease in rural residents was higher than urban residents. In contrast to our study in Hamadan and Isfahan provinces, the rate of urban cases was more than rural areas $(6,14)$. The incidence of disease in urban or rural areas, as well as in certain occupations, is due to the difference in the epidemiological cycle of the disease (agents, vectors, reservoirs, and biological differences) in different geographical regions.

In Isfahan, due to the fact that more people live in the cities that are located on or near colonies of gerbil rodents and also phlebotomine sandflies as vectors exist. Therefore, all conditions for the transmission of the disease are available in this endemic urban area. But in our study, due to the fact that the residents of rural areas were more exposed to infected reservoirs and vectors, more cases were reported from these areas.

According to our findings, most lesions were on the hands and the least were on the trunk. And also most of the patients had 1 lesion on their body. In Isfahan, Fars, Khuzestan, and Ilam provinces, their results were completely sim- 
ilar to ours (6,11,15-18). In Andimeshk, most lesions were on the hands and feet (12). In Hamedan, most patients had 1 to 2 lesions on their hands and feet (71.6\%) (14). Due to the fact that sandflies are not able to bite their host through clothing, lesions are often seen on uncovered areas such as hands, feet and face. Also, the number of lesions on the body indicates multiple exposures to disease vectors and number of bites.

In accordance with other studies, most cases of disease occurred in autumn and the least cases occurred in spring $(6,12,13,16,18)$. In studied area the activity of sandflies is typically seasonal and there is a main peak of activity in the end of April. Considering that there is usually a 6-month incubation period for cutaneous leishmaniasis, therefore the symptoms of the disease appear in autumn.

The most important limitation of our study was that, some of the leishmaniasis cases did not go to the health centers actively, so in some period of time active case finding was done instead of routine process (passive method) in order to find all cases in these important endemic foci.

\subsection{Conclusions}

Marvdasht city is an endemic area of cutaneous leishmaniasis in Iran. According to the results, the incidence of disease was higher in men and mostly occurred in rural areas in autumn. As a result, targeted preventive measures (vector control, reservoir control, case finding and treatment, health education, etc.) should be taken by health authorities and decision makers based on the basic information of high risk population and other epidemiological and ecological factors affecting the transmission of disease in this endemic area.

Our results showed that the number of cases reported has fluctuated in recent years. Therefore, it is very important for the health system to implement an accurate and effective continuous monitoring strategy for this important vector-borne disease in this part of the country.

\section{Acknowledgments}

We are grateful to all the participants in this study. Authors are grateful to the assistance of Marvdasht health center staff, Shiraz University of Medical Sciences (SUMS).

\section{Footnotes}

Authors' Contribution: Jalal Mohammadi and Aboozar Soltani carried out the experiment. Aboozar Soltani wrote the manuscript with support from Jalal Mohammadi conceived the original idea. Aboozar Soltani supervised the project.
Conflict of Interests: All authors declare that they have no conflict of interest.

Ethical Approval: None declared by the author.

Funding/Support: The authors received no specific funding for this work.

\section{References}

1. Torres-Guerrero E, Quintanilla-Cedillo MR, Ruiz-Esmenjaud J, Arenas R. Leishmaniasis: A review. F1000Res. 2017;6:750. doi: 10.12688/f1000research.11120.1. [PubMed: 28649370]. [PubMed Central: PMC5464238].

2. McMichael AJ. Globalization, climate change, and human health. $N$ Engl JMed.2013;368(14):1335-43. doi:10.1056/NEJMra1109341. [PubMed: 23550671].

3. Dabaghmanesh T, Asgari Q, Moemenbellah-Fard MD, Soltani A, Azizi K. Natural transovarial and transstadial transmission of Leishmania infantum by naive Rhipicephalus sanguineus ticks blood feeding on an endemically infected dog in Shiraz, south of Iran. Trans $R$ Soc Trop Med Hyg. 2016;110(7):408-13. doi: 10.1093/trstmh/trw041. [PubMed: 27496515].

4. Nazari M, Taravatmanesh G, Kaveh MH, Soltani A, Ghaem H. The effect of educational intervention on preventive behaviors towards cutaneous leishmaniasis at Kharameh city in 2014. Shiraz E Med J. 2016;17(10). doi:10.17795/semj39957.

5. Azizi K, Soltani A, Alipour H. Molecular detection of Leishmania isolated from cutaneous leishmaniasis patients in Jask county, Hormozgan province, southern Iran, 2008. Asian Pac J Trop Med. 2012;5(7):5147. doi: 10.1016/S1995-7645(12)60090-X. [PubMed: 22647811].

6. Nilforoushzadeh MA, Shirani Bidabadi L, Hosseini SM, Fadaei Nobari $\mathrm{R}$, Jaffary F. Cutaneous leishmaniasis in Isfahan province, Iran, During 2001-2011. J Skin Stem Cell. 2014;1(2). e23303. doi:10.17795/jssc23303.

7. Ershadi MR, Zahraei-Ramazani AR, Akhavan AA, Jalali-Zand AR, Abdoli H, Nadim A. Rodent control operations against zoonotic cutaneous leishmaniasis in rural Iran. Ann Saudi Med. 2005;25(4):309-12. doi: 10.5144/0256-4947.2005.309. [PubMed: 16212124]. [PubMed Central: PMC6148012]

8. Kalantari M, Motazedian MH, Asgari Q, Soltani Z, Soltani A, Azizi K. Bionomics of phlebotomine sand flies species (Diptera: Psychodidae) and their natural infection with Leishmania and Crithidia in Fars province, southern Iran. J Parasit Dis. 2018;42(4):511-8. doi: 10.1007/s12639-018-1027-6. [PubMed: 30538348]. [PubMed Central: PMC6261151]

9. Torgerson PR, Macpherson CN. The socioeconomic burden of parasitic zoonoses: Global trends. Vet Parasitol. 2011;182(1):79-95. doi: 10.1016/j.vetpar.2011.07.017. [PubMed: 21862222].

10. Azizi K, Kalantari M, Motazedian MH, Asgari Q, Mohammadpour I, Soltani A. Co-detection and isolation of Leishmania and Crithidia among naturally infected Tatera indica (Rodentia: Muridae) in Fars province, southern Iran. Asian Pac JTrop Biomed. 2018;8(5):279-84. doi: 10.4103/2221-1691.233010.

11. Norouzinezhad F, Ghaffari F, Norouzinejad A, Kaveh F, Gouya MM. Cutaneous leishmaniasis in iran: Results from an epidemiological study in urban and rural provinces. Asian Pac JTrop Biomed. 2016;6(7):614-9. doi:10.1016/j.apjtb.2016.05.005.

12. Hassanpour K, Aghamollaei H, Golpich M, Amani J, Taheri A, Farnoosh G. Molecular epidemiological study of cutaneous leishmaniasis in the east north of Iran. Asian Pac J Trop Dis. 2014;4:540-4. doi: 10.1016/s2222-1808(14)60673-3.

13. Barati H, Barati M, Lotfi MH. [Epidemiological study of cutaneous leishmaniasis in Khatam, Yazd province, 2004-2013]. Param Sci Mil Health. 2015;10(2):2-5. Persian. 
14. Zahirnia A, Moradi A, Nouroozi N, Naderbothaie S, Erfani $\mathrm{H}$ Moradi A. [Epidemiological survey of cutaneous leishmaniasis in Hamadan province (2002-2007)]. J Hamadan Univ Med Sci Health Serv. 2009;16(1):43-7. Persian.

15. Jafarnezhad A, Jamshidi F, Dehghan A. [Evaluation of cutaneous leishmaniasis in the city of Lamerd in 2004-2014]. Med J Mashhad Univ Med Sci. 2017;60(1):376-82. Persian.

16. Fakoorziba MR, Eghbal F, Eghbal H. Surrey on some epidemiological factors of cutaneous leishmaniasis in Fars Province of Iran. Int J Infect Dis. 2012;16:e158-9. doi:10.1016/j.ijid.2012.05.689.
17. Feiz-Haddad MH, Kassiri H, Kasiri N, Panahandeh A, Lotfi M. Prevalence and epidemiologic profile of acute cutaneous leishmaniasis in an endemic focus, Southwestern Iran. J Acute Dis. 2015;4(4):292-7. doi: 10.1016/j.joad.2015.06.007.

18. Askari MB, Fakoorziba MR, Kalantari M, Alavi A, Azizi K. Some ecological aspects of phlebotomine sand flies (diptera: Psychodidae) in an endemic area of leishmaniasis in darab district, Fars province, southern Iran. Ann Trop Med Pub Health. 2017;10(1):182. doi: 10.4103/17556783.205584 . 